\title{
Integrating a Voice of Customer to Create the Customer Needs Quality Function Deployment (CN- QFD) for a Sustainable New Product Development
}

\author{
Thanyatorn Fongsatitkul \\ Graduate School of Systems Design \\ Tokyo Metropolitan University, Tokyo, Japan 191-0065 \\ E-mail: thanyatorn_f@hotmail.com (Corresponding Author) \\ Yasutaka Kainuma \\ Graduate School of Systems Design \\ Tokyo Metropolitan University, Tokyo, Japan 191-0065 \\ E-mail: kainuma@tmu.ac.jp
}

\begin{abstract}
Questionnaires are effective tools which are commonly used for collecting survey data regarding the actual customer needs. On-line questionnaire/satisfaction surveys are indispensable to obtain accurate results concerning the customer needs. Such information is required to develop the customer needs quality function deployment (CN-QFD) for creating a new sustainable one-handed lipstick packaging. Such surveys use a combination of Telrad's questionnaire procedure to include or exclude the questionnaire in accordance with the mission requirements and the Hybrid QFD Framework to develop a new product. A detailed analysis of the satisfaction survey results reveals the actual customer needs which can be further incorporated into the engineering characteristics. After excluding a number of the questionnaires, the remaining ones could be further modified and become the critical parts to construct the final QFD to form the House of Quality (HoQ). In this study, several designed alternatives were considered and the best resolution alternative for the sustainable one-handed lipstick packaging was selected and prototyped accordingly with the supports of SolidWorks Software and 3D Printer. The round-shape casing encourages keeping the lipstick in the palm of the hand, thus enabling the easy use of the slide-up and -down mechanism. The cap lid flips up conveniently using only onehand, which provides a better opportunity to be used suitably and effectively at all times. Finally, the lipstick casing can be reused and the severed ring at the sleeve can also be twirled and removed conveniently which minimizes the waste of lipstick content.
\end{abstract}

Keywords: voice of customer, Telrad's questionnaire procedure, hybrid QFD framework, customer needs quality function deployment (CN-QFD), sustainable development, new product development.

\section{INTRODUCTION}

New product development (NPD) is nowadays one of the most crucial factors for business success. Good product planning is then crucial to ensure the success of NPD which is mostly depended on the product development and distribution. There are many different processes that companies used to develop new products; however, one of the most distinguish processes is the concept of a funnel or "stage gate" system called the four distinct stages. The model aims to guide developers and/or managers through the NPD process starting from idea development through the product launch. It includes four distinct stages as discovery (generate innovation ideas), define (product concept and specification), develop (product development and testing), and deliver (product launch). Product acceptation is also significantly based on the qualities of product design with an integration of engineering needs derived predominantly from consumer's requirements. In parallel with this endeavor, the rapid growing and wide spreading of green manufacturing that relates to environmental issues in various industrial sectors have been steadily accelerated. Sustainable new product development (SNPD) has then become one of the most important issues for the manufacturing industry, forcing the industry to increase its awareness towards the environment and produce products which meet both the customer needs and environmental requirements. NPD ultimately needs to be shifted from the transitional stage to the sustainable products and technologies domain, focusing on reengineering, clean technologies, products purchasing, use, and disposal. This would encourage closer teamwork in the future among manufacturing managers who are in charge of product development, marketing, and environmental protection and control.

Along with this development, lipstick which is one of the most commonly used cosmetic products, has significantly increased. Conventional lipsticks have appeared to be in the same shape or packaging with a twisting-roller cover cap for several decades, while the other cosmetics have been changed significantly. During the years 2019-2025, it is also predicted that the compound annual growth rate (CAGR) of the global lipstick market will reach $7.4 \%$ with the amount of USD 18.9 billion by 2025 (Grand view research, 2019). To help accelerating the CAGR of the global lipstick market, a proper redesign of lipstick packaging must be initiated in accordance with the customer's demands for a new innovation, convenience, and satisfaction. One of the key challenges to redesign is how to 
serve the working woman, teenager, and elderly to apply the lipstick in the public as conveniently and quickly as possible. This challenge can be solved effectively by designing the new sustainable lipstick packaging using a one-hand opening. In terms of product sustainability, minimizing the left-over content and maximizing the use of the remaining content at the bottom of the compartment will be the most effective ways to help saving the cost and the world ecosystem. The lipstick packaging redesign and modification to minimize the unused lipstick leftover is then one of the proposed ideas, focusing principally to initiate a new design of one-handed sustainable lipstick packaging.

Manufacturers generally cannot afford a costlyredesign and full-cycle operation in the long term. Product acceptation is based on the qualities of product design with an integration of engineering needs derived from consumer requirements and environmental considerations into the QFD methodology to design and create eco-friendly products, namely, the House of Quality (HoQ). In such cases, QFD can be effectively used to incorporate all customer requirements in engineering specifications for designing a new sustainable product. Questionnaires are commonly designed and employed to accumulate the survey data for many different purposes in accordance with the customer needs. Generating suitable survey questionnaires in both open-ended and close-ended ones and creating an appropriate analytical methodology are the two most important devices to gain accurate results. This study, therefore, aimed to: 1) create an effective voice of customer (VOC) questionnaire survey and analysis in conjunction with the CN-QFD, and 2) construct the final CN-QFD in the form of House of Quality (HoQ) and identify as well as evaluate all possible options of packaging with respect to minimizing the non-used lipstick content in accordance with the required criteria. The best resolution alternative of the sustainable one-handed lipstick packaging was chosen and prototyped accordingly with the supports of SolidWorks Software and 3D Printer. The paper was carefully structured step-by-step as follows; a background and justification of SNPD-VOC, and CN-QFD was described in section 1, a related literature review covering SNPD processes-questionnaire survey-QFD was identified in section 2, and followed by section 3: research methodology including a combination of the strength of the Telrad's questionnaire methodology and certain appropriately modified procedures of the hybrid QFD were considered and developed as a novel supporting tool, named "CN-QFD". It also covered the questionnaire survey and analysis of customer requirements both open-end and closed-end questionnaires and CN-QFD. In section 4: results and discussion, it illustrated the results and discussion of those mentioned in section 3. Finally, conclusions and future research directions were presented in section 5 .

\section{RELATED LITERATURE REVIEWS}

The NPD process has been extensively studied and reported in the literature, including initial product selection and development, commercialized evaluation, and product manufacturing and marketing. Wu and Pagell (2011) indicated that a shift towards green products and production processes which, in turn, implies that environmental factors may become the norm in the near future regarding manufacturing. To maintain such a platform, manufacturing should focus on producing environmentally friendly products with a minimal usage of non-renewable resources, climate-change free emissions, and sustainable disposal systems (Wolf and Seuring, 2010). Williams and Kennedy (2017) indicated that sustainable supply chain management (SSCM) appeared to be an effective strategy to survive in the future global market. Nowadays, industries across the world have effectively integrated SSCM into their all-inclusive systems (Hassini and Surti, 2012). SSCM practices, for example, environmentally supportive packaging, 3R (reuserecycle-recovery) of the already-consumed products, and an effective disposal system, could encourage society to move towards sustainability (Lin and Tseng, 2016). Das (2020) proposed the model to integrate the overall operating costs relating to the selected life cycle assessment (LCA) metrics in procurement, production, collection of returns, recovery, reuse, remanufacturing, transportation, and distribution of products to attain environmental and economic sustainability. Das and Mitra (2018) integrated all relevant factors and practices of environmental and economic sustainability as well as social responsibility in the supply chain (SC) design and planning to elaborate its overall performance. The research outcomes showed effectiveness of the proposed target-based planning to pinpoint crucial sustainability indices and selected appropriate options to improve the indices and overall performances within desirable bounds on cost. Tundys (2018) focused largely on aspects of quantitative statistical methods that were used to assess individual elements of a supply chain, as well as a holistic approach to the evaluation of the entire chain. It aimed to identify the mathematical, statistical and operations research tools as well as management tools used to assess the activity, performance and level of the greening of the supply chain. Mujkić (2018) enhanced understanding how to incorporate sustainability principles into mathematical models for SC optimization and provided SC optimization models with pertinent sustainability indicators.

Curtis and Ellis (1998) specified that a successful product development depended on a proper understanding and focusing on the actual customer needs, especially in time-limitation and high-competition environments. Dimancescu and Dwenger (1996) also indicated that one of the most common problems concerning the customer requirements was how to identify and describe them clearly and effectively. It is crucial that systematic and comprehensive techniques be created to obtain and analyze the customer needs and reduce the possibility of process collapse. Survey questionnaires are an effective tool to help solving such a problem, however; a reliable survey questionnaire should be carefully developed to avoid potential pitfalls. Parasuraman (1991) described several key components in constructing a survey questionnaire, including a number of tips and tricks to enhance its reliability. New product development method applying the Kano's Quality model was established. The method results in a high customer satisfaction (CS) considering in term of the quality model (Kainuma and Amano, 2018).

To evaluate survey questionnaires effectively, QFD is widely considered an efficient tool to establish proper product specifications. Romero-Hernández (2021) proposed 
a novel modified Quality Function Deployment (QFD) based supply chain selection methodology to serve the unfolding needs of startups. The QFD methodology was adapted to accommodate for the assessment and selection of supply chain configurations which incorporated a series of factors including supply chain needs, technical specifications, relationships among specifications, and potential synergies. Sullivan (1986) indicated that QFD is a conceptual strategy to transfer the customer requirements into technical ones at all stages of production processes and development. This led to the introduction of the House of Quality (HoQ) - a matrix generating a conceptual map to help processing the product blueprint. Traditionally, QFD practices were constantly disregarded to determine the target values of engineering characteristics. To overcome such shortcomings, several QFD supporting tools, namely, Case-Based Reasoning (CBR), Analytic Hierarchy Process (AHP), Fuzzy logic, and the Kano questionnaire have been utilized under different schemes and conditions. In addition, Telrad's questionnaire methodology has been commonly used for generating or eliminating the questionnaire in accordance with the required procedures. A combination of CBR, AHP, and fuzzy logic has also been employed jointly in the case of Hybrid QFD (HQFD). CBR is an experience-based method which adapts previously satisfactory solutions to solving a new problem with the support of artificial intelligence techniques (Kolodner, 1993). An AHP can be applied to reveal the significance of customer needs with pairwise comparisons (Chuang, 2001). Fuzzy logic has been employed to convey linguistic data to crisp scores for further calculation of the inclusive customer satisfaction (Bouchereau and Rowlands, 2000).

To help tackle the deficiencies of the traditional QFD strategy it is necessary to incorporate the customer requirements as much as possible by using the HQFD planning tool (Tsai et al., 2002) as well as the Telrad's questionnaire methodology (The elimination and addition procedure) (Glushkovsky et al., 1995), known as the customer needs quality function deployment (CN-QFD). Wang et al, (2019) identified the survey issues on the questionnaire and the satisfaction scores of the final important ratings of customer requirements regarding a simple food product. This was achieved by employing fuzzy logic both in surveys and group interviews, as well as substituting the absolute values of relative technical ratings with priority rankings.

\section{METHODOLOGY}

A combination of the strength of the Telrad's questionnaire methodology and certain appropriately modified procedures of the hybrid QFD were considered and developed as a novel supporting tool, named "CN-QFD". The overall conceptual flow diagram of the design on a sustainable new product development as shown in Figure 1 can be summarized as follows:

\subsection{Questionnaire Survey and Analysis of Customer Requirements}

3.1.1 Open-Ended Questionnaire Survey and Data Analysis

Survey questionnaires relating to both product and package were initiated and distributed with non-likelihood sampling to Thai women aiming to collect the data of about 30 respondents. The questionnaires, intending to document the user's experiences and opinions as precisely as possible, were composed of 3 major portions as background information (demographic data), consumption behaviors, and idea, attitudes and suggestions, focusing on an assessment of the user's background and behavior, attitudes, motivation, and actual requirements. Those evaluating the user's preferences and product discernment were used to pinpoint the real user requirements and corresponding importance.

Some questions relating to the product, for example; asking about "What kinds of functions do you expect from lipstick packaging?" or "Have you ever concerned about the rest of lipstick's content after running out?" were discussed step-by-step among the members of the focus group to finalize the lists of all quality dimensions. These included the issues identified from customer needs concerning the onehanded lipstick as well as the target customers' lists of the positive examples of each quality dimension. A set of appropriate questions and engineering characteristics was established to further explore the correlation between questions and engineering objectives by putting interrelationship symbols with an elimination of the questions according to the procedure.

\subsubsection{Close-Ended Questionnaire Survey and Data Analysis}

Designed satisfaction survey questionnaires were distributed on-line and induced approximately 90 individual responses. The survey results were collected and analyzed with the integrated support of a fuzzy logic process. Afterwards, satisfaction levels were counted as the respondent number per level, followed by calculating the category average $(\mathrm{Cj})$ and response quality $(\mathrm{Qk})$. A comparison between $\mathrm{Cj}$ and $\mathrm{Qk}$ was then made with each $\mathrm{Cj}$ variation and finally the usable engineering specifications for design purposes were initiated accordingly.

\subsection{Customer Needs Quality Function Deployment (CN-QFD)}

A voice of customers (VOCs) survey was conducted and then analyzed and interpreted with respect to the customer needs and priorities. The final usable specifications were pinpointed according to each customer needs and the relationship matrix of each customer needs and specification was established. This was followed by a comparison among the conventional and competitors' products. A technical assessment comparing the existing specifications available in the market was then initiated, aiming to finalize the product target. Typically, the highest rank specifications are significantly related to the customer requirements, serving as the important product features.

Subsequently, the corresponding matrix presenting the relation among each specification was created. Furthermore, several possible design alternatives of the new lipstick compartment were generated and compared by calculating the scores in accordance with those of the required criteria. The best possible alternative of the sustainable one-handed lipstick packaging was selected and prototyped accordingly with the supports of SolidWorks Software and 3D Printer. 


\section{Conceptual flow diagram of the design on a sustainable new product development}

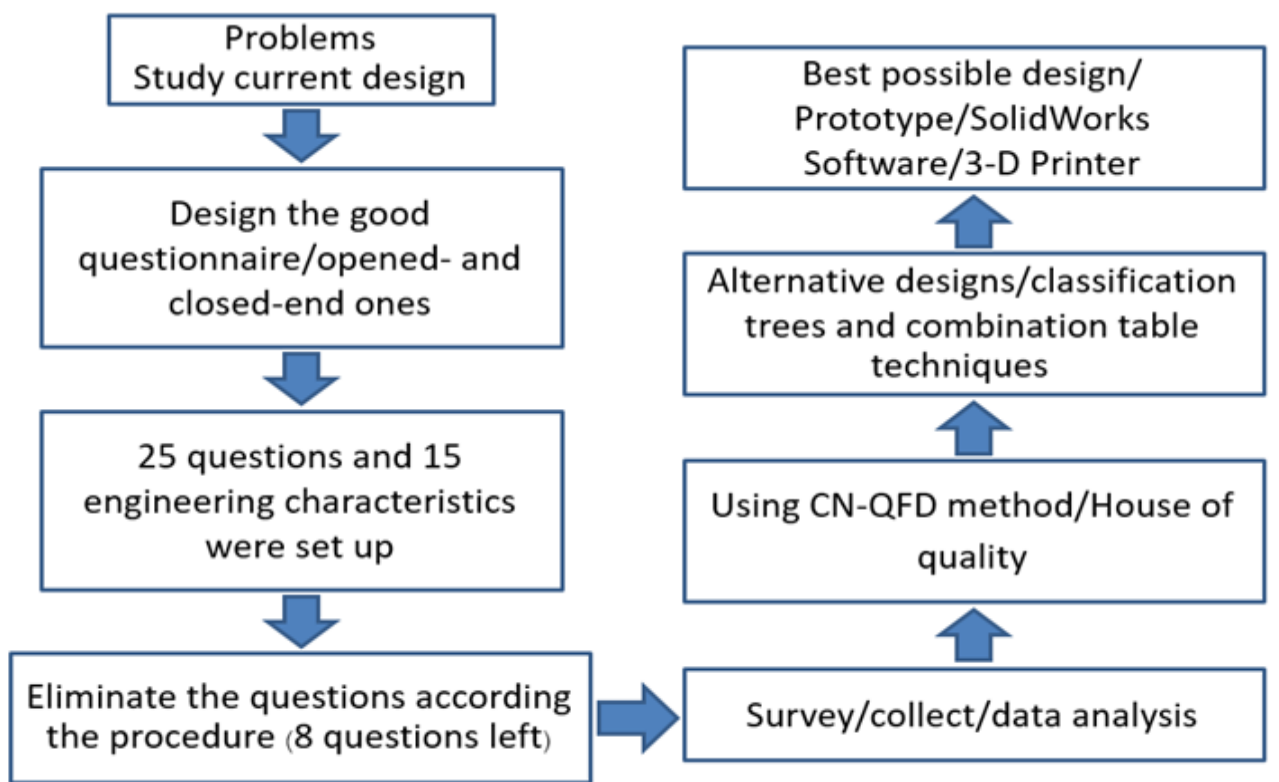

Figure 1 Conceptual flow diagram of the design on a new product development

\section{RESULTS AND DISCUSSION 4.1 Customer Needs and Satisfaction Questionnaire Surveys and Data Analysis}

Quality dimensions related to the customer requirements for the sustainable one-handed lipstick packaging were categorized as accomplishment, attributes, trustworthiness, conformance, aesthetics, and recognizable quality. Target customers identified the lists of the positive issues under each quality dimension which can further serve as the input for the development of QFD as shown in Table 1. Survey questionnaire design of about 25 closed-ended questions was then initiated and 17 questions were eliminated according to the procedure with the 8 remaining questions for further usage. Afterwards, satisfaction levels were counted as the respondent number per level, followed by calculating the category average $(\mathrm{Cj})$ and response quality (Qk). A comparison between $\mathrm{Cj}$ and $\mathrm{Qk}$ was then made with each $\mathrm{Cj}$ variation and finally the usable engineering specifications for design purposes were initiated accordingly as shown in Figure 2. The combination of 8 customer needs and 7 engineering objectives comprised the finalized set of usable engineering specifications to develop the sustainable one-handed lipstick packaging. The seven engineering objectives include: lipstick case dimension, lipstick weight, applying time requirements, minimum time needed to open the lid or twist up, lifetime, resistance to the environment, and resistance to scratches. Details of the satisfaction score survey on the sustainable one-handed lipstick packaging, including demographic data and consumption habits were illustrated in Figure 3. It is then interesting to reveal that the key satisfaction survey of the customer needs were as easy to use, following industry standards and specifications, easy opening methods, modern and beautiful lipstick case, environmental-friendly, reduce lipstick waste, light weight, and reusable lipstick case of with the satisfaction scores at the highest level (level 5: fully satisfied) of about 60.6, 46.8, 51.1, 45.7, 45.7, 43.6, 43.6, and 23.4, respectively. These parameters were used as crucial inputs for the development of CN-QFD in the form of House of Quality (HoQ). 
Table 1 Positive issues under different quality dimensions and actual customer needs for further integration as engineering specifications to develop the sustainable one-handed lipstick packaging

\begin{tabular}{|c|c|c|}
\hline Quality Dimensions & Positive issues & Actual customer needs \\
\hline Accomplishment & $\begin{array}{l}\text { Reusable lipstick case } \\
\text { Easy to hold (does not roll) } \\
\text { Refillable lipstick case } \\
\text { Safety to use }\end{array}$ & $\begin{array}{l}\text { Reusable lipstick case } \\
\text { Easy to hold (does not roll) } \\
\text { Refillable lipstick case } \\
\text { Safety to use }\end{array}$ \\
\hline Attributes & $\begin{array}{l}\text { Opening methods (Twist up, Sliding up and down and Flip-open } \\
\text { cap) } \\
\text { Short opening time } \\
\text { Light weight } \\
\text { Lock methods }\end{array}$ & $\begin{array}{l}\text { Easy opening methods } \\
\text { Light weight } \\
\text { Portable } \\
\text { Compact size } \\
\text { Compact shape }\end{array}$ \\
\hline Conformance & $\begin{array}{l}\text { Material meets industry standards and specifications } \\
\text { Environmental-friendly }\end{array}$ & Environmental-friendly \\
\hline Trustworthiness & $\begin{array}{l}\text { Be durable } \\
\text { Long-life usage } \\
\text { Have a certification (Certified by FDA, ISO9001:2008 or etc.) }\end{array}$ & $\begin{array}{l}\text { Durable } \\
\text { Following industry standards and } \\
\text { specifications: } \\
\text { Have a certification (Certified by FDA, } \\
\text { ISO9001:2008 or etc.) }\end{array}$ \\
\hline Aesthetics & $\begin{array}{l}\text { Modern and beautiful lipstick case } \\
\text { Multi-color lipstick case } \\
\text { Luxury design }\end{array}$ & Modern and beautiful lipstick case \\
\hline Recognizable Quality & $\begin{array}{l}\text { Reasonable price match with quality } \\
\text { Brand name with high quality lipstick case } \\
\text { Easy to use } \\
\text { Reduce lipstick waste }\end{array}$ & $\begin{array}{l}\text { Reduce lipstick waste } \\
\text { Easy to use }\end{array}$ \\
\hline
\end{tabular}

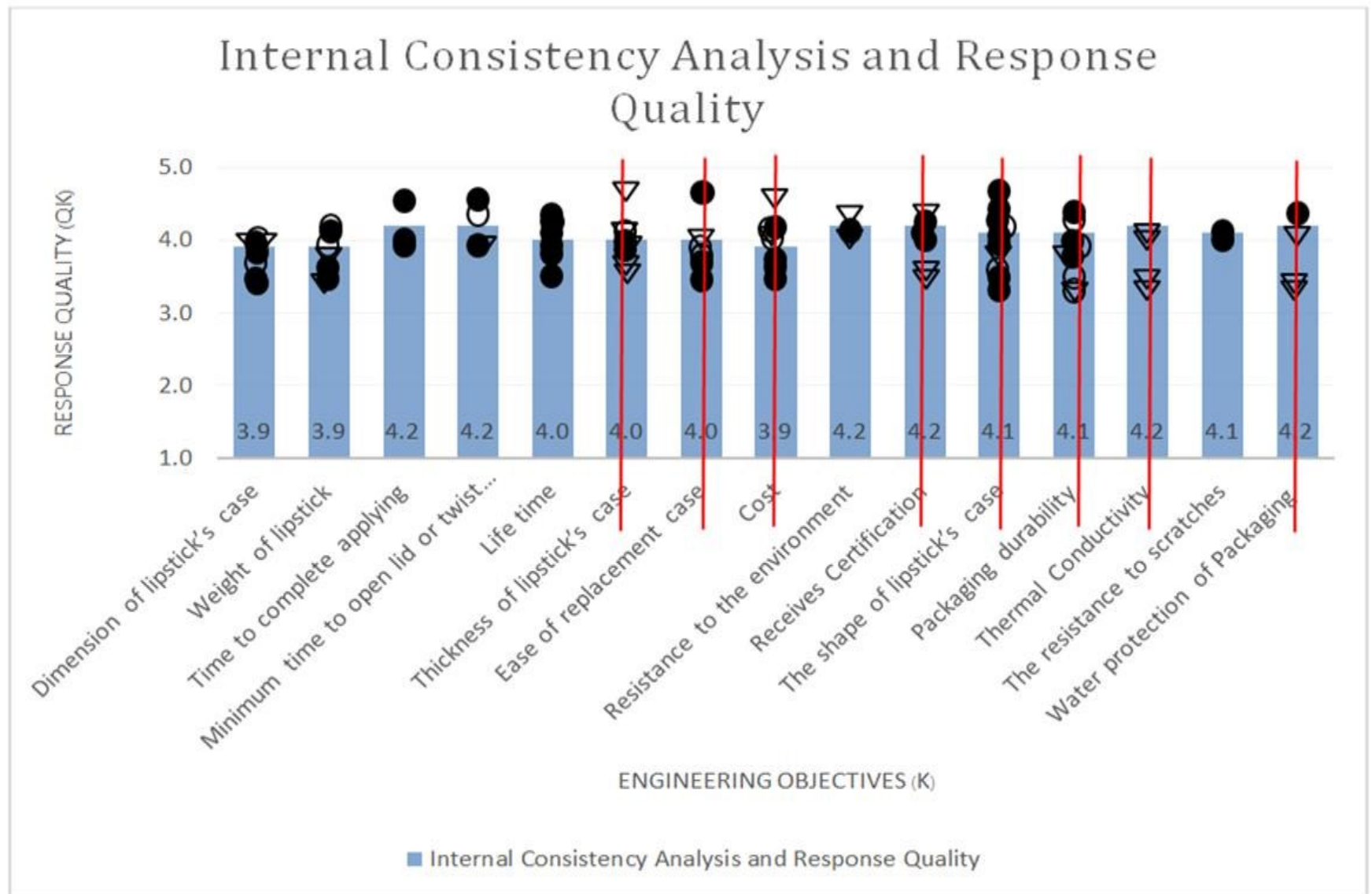

Figure 2 Internal consistency analysis of response quality among each engineering objective and the final engineering specifications used for design purpose 
Part 1: Background information (demographic data)

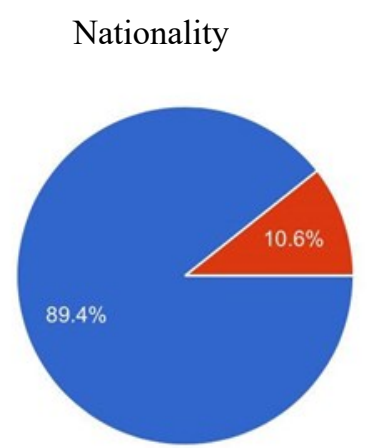

Educational qualification

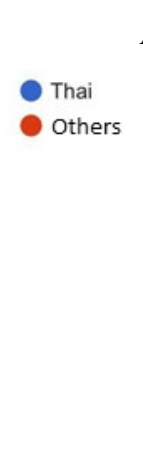

Age (years)

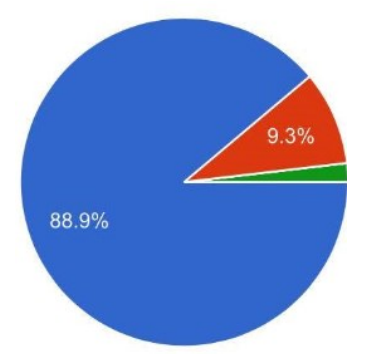

Monthly income (Baht)

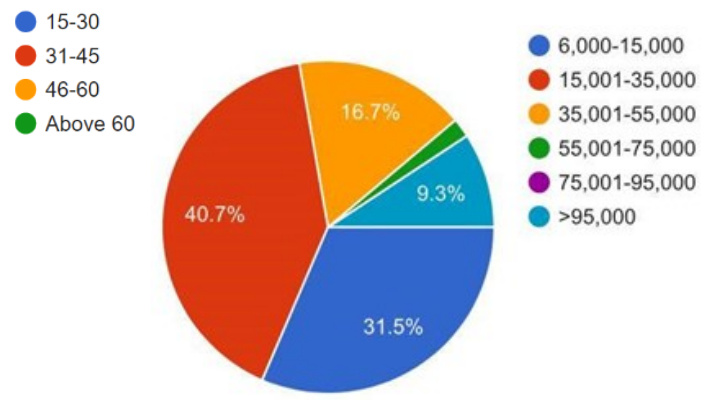

Occupation
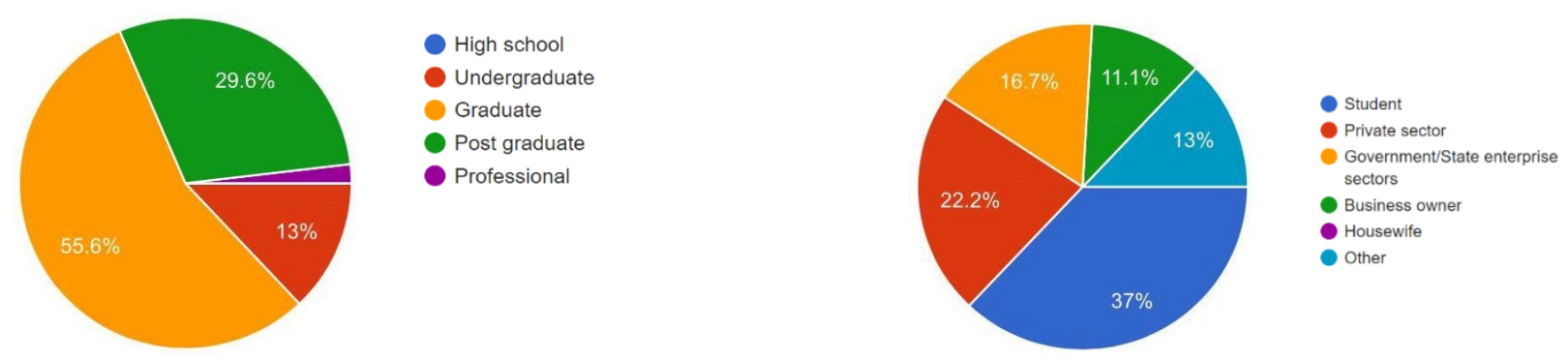

Part 2: Consumption behaviors: satisfaction score (\%) of the one-handed sustainable lipstick packaging

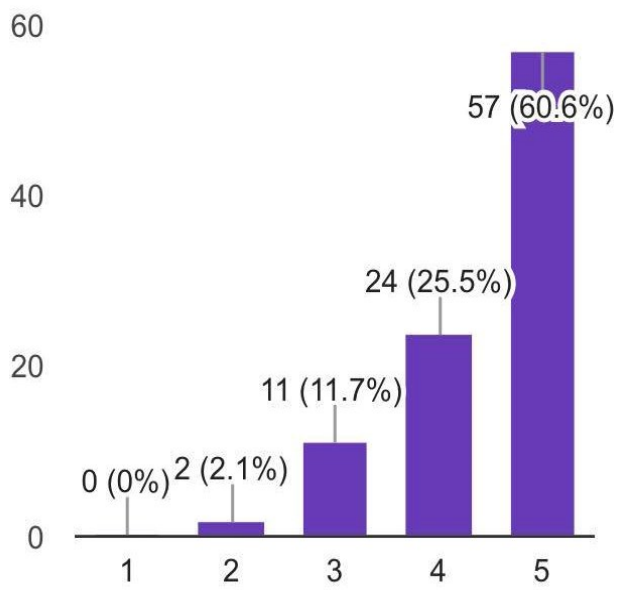

"Easy to use"
40 $34(36.44)(46.8 \%)$

20

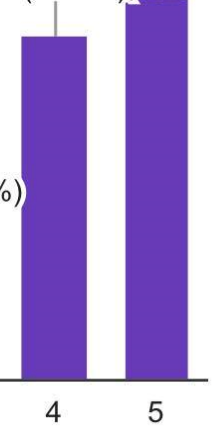

"Following industry standards and Specifications" 


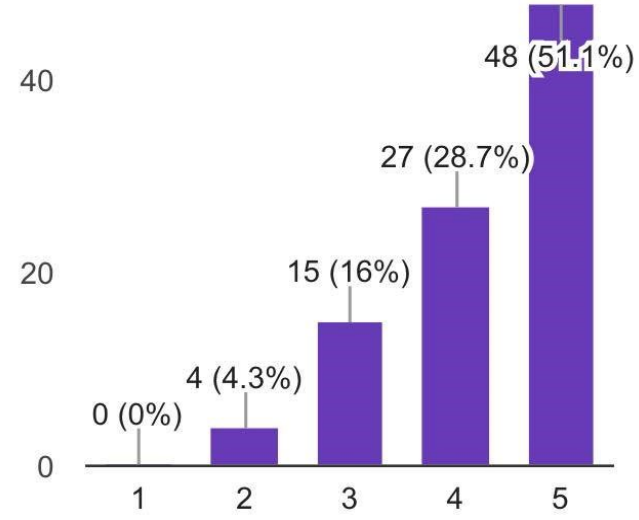

"Easy opening methods"

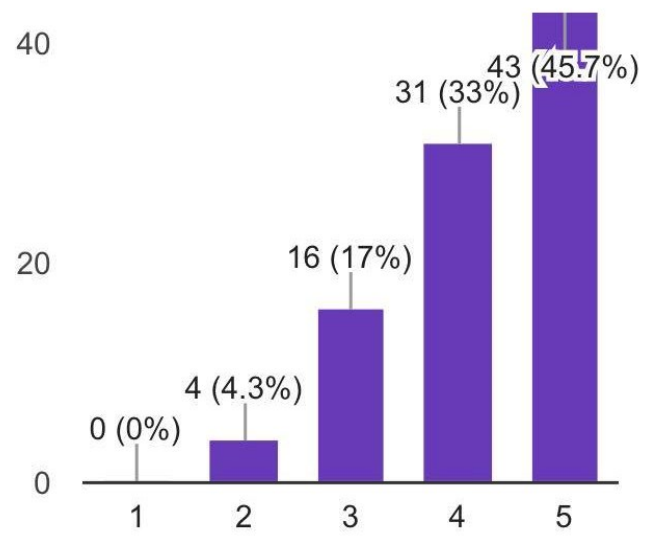

"Environmental-friendly"

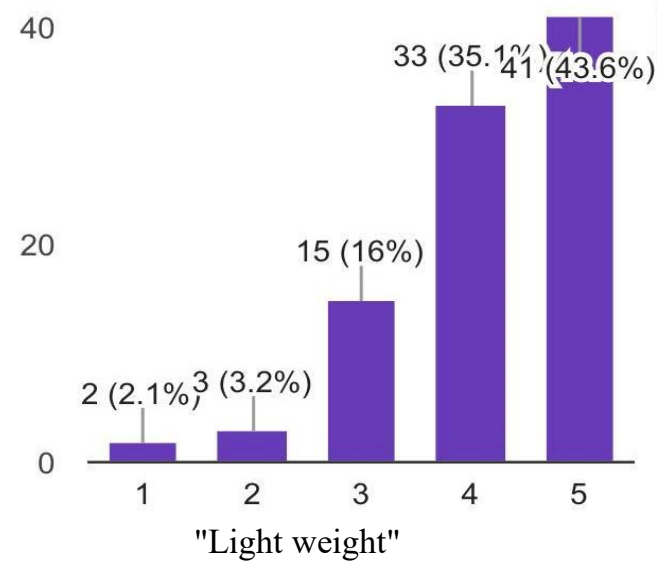

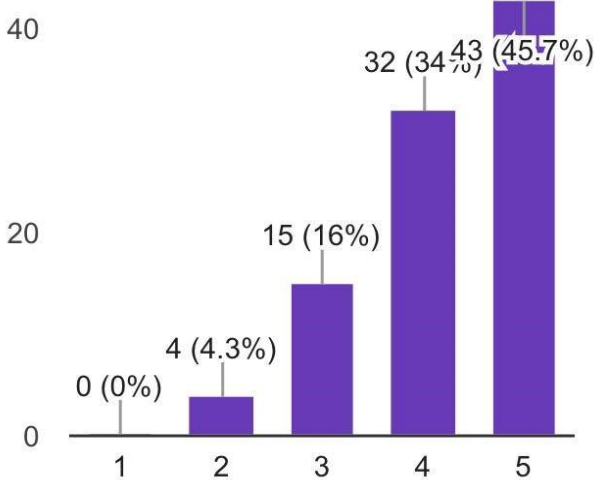

"Modern and beautiful lipstick case"

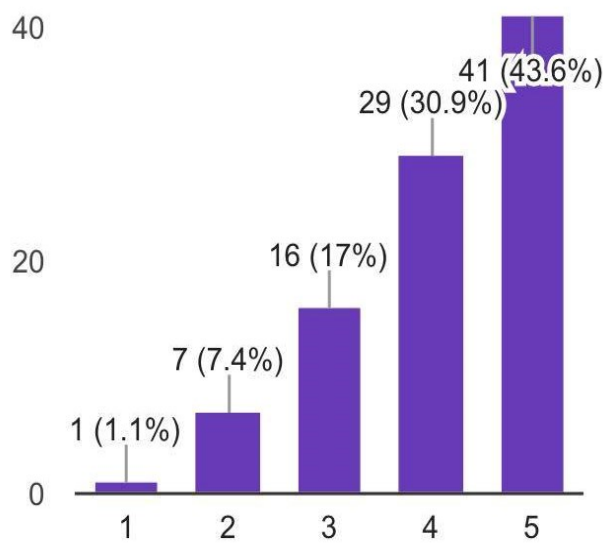

"Reduce lipstick waste"

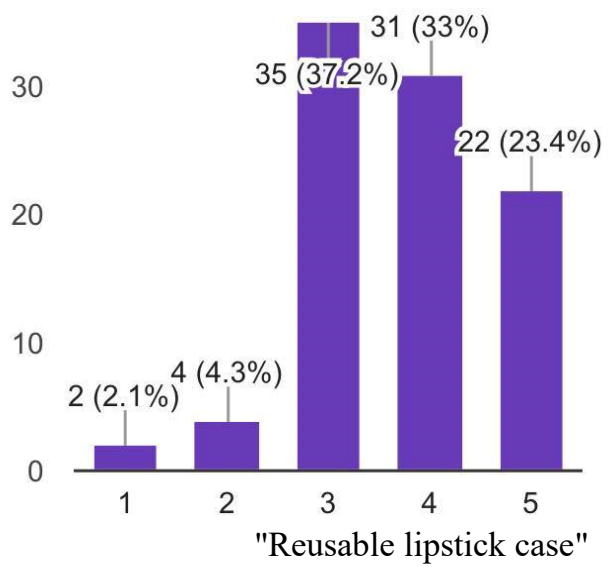

Figure 3 Satisfaction survey on the sustainable one-handed lipstick-packaging

Note: Degree of satisfaction were assigned as; $1=$ very poorly satisfied, $2=$ poorly satisfied, $3=$ moderately satisfied, $4=$ highly satisfied, $5=$ fully satisfied

\subsection{Customer Needs - Quality Function Deployment (CN-QFD)}

The important keys of customer needs were prioritized and ranked in accordance with the required criteria and procedures. This included the following keys: easy to use, easy opening methods, reduce lipstick waste, sustainable, and follow material industry standards and specifications.
Representative examples of data analysis of the sustainable one-handed lipstick packaging, named the House of Quality (HoQ), were illustrated in the Figure 4. All highest rank specifications relating significantly with the voices of customers were served as key features for the new product development. They included the key features as; easy to use, easy opening methods, and reduce lipstick waste which were 
ranked 1, 2, and 3, respectively as shown in Figure 4. Possible options were then carefully considered and initiated for those three key design features; easy opening methods (slide up and flip open), easy to use (round-, square- , and oval-shapes), reduce lipstick waste (peel the tube off and detach/twist off the plastic ring). In addition, scoring criteria for the important ratings of the key customer needs (easy to use, following industry standards and specifications, easy opening methods, modern and beautiful lipstick case, environmental-friendly, reduce lipstick waste, light weight, and reusable lipstick case) were assigned as 9, 9, 9, 9, 9, 7, 7 , and 5 , respectively in accordance with those satisfaction scores at the highest level (level 5: fully satisfied) as shown in Figure 5.

A new product development was then established in according to those possible options of the key design features starting from concept generation and possible design alternatives, followed by design screening, scoring, and selection. Each alternative would be illustrated as a sketch or as a rough three-dimension model with a short textual description. Based on these key elements, all possible alternatives of 10 different designs using classification trees and combination table techniques were finally generated as shown by Figure 6.

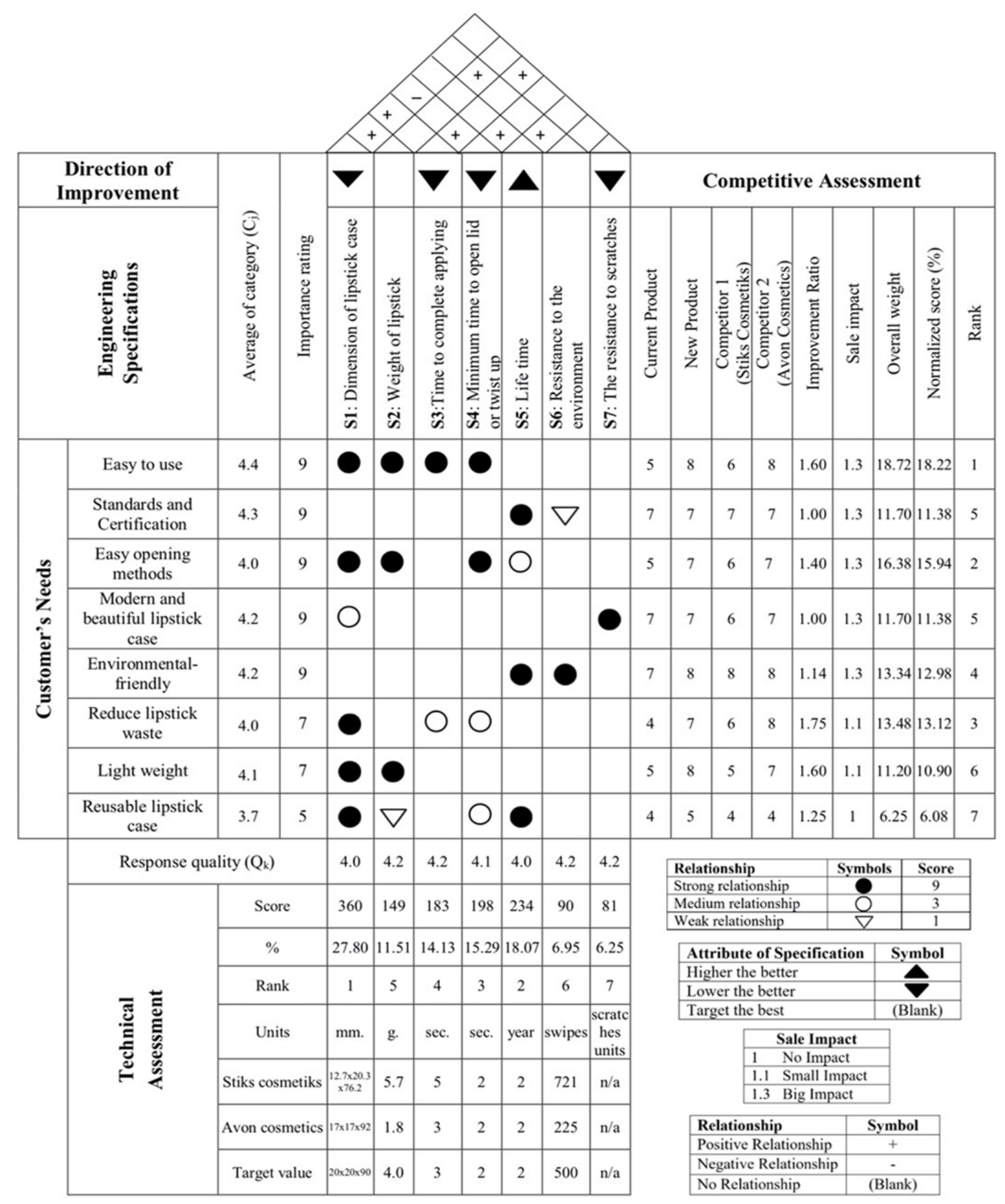

Figure 4 House of quality (HoQ) for customer needs quality function deployment (CN-QFD) 


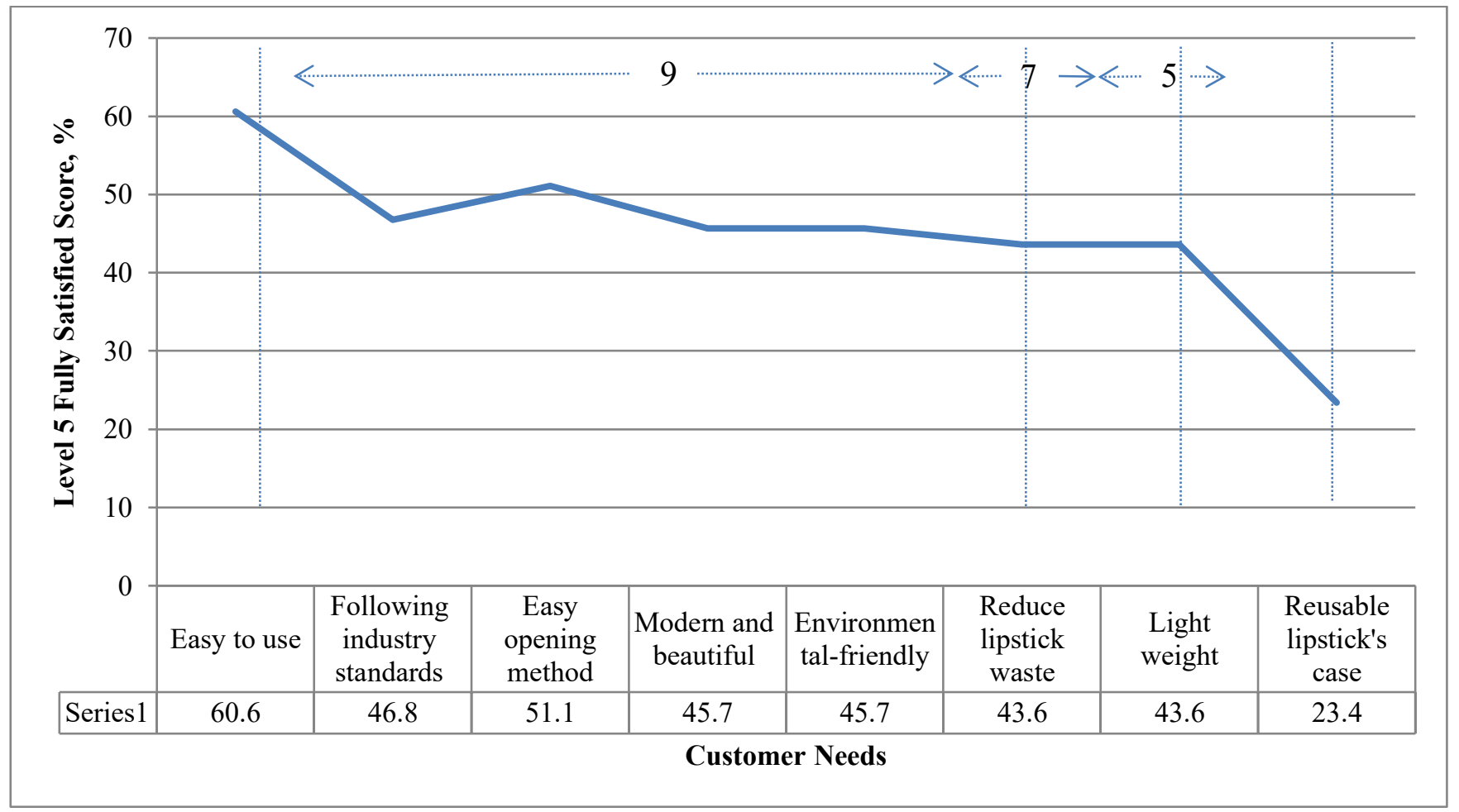

Figure 5 Scoring criteria establishment for important rating $(9,7,5)$ of the customer needs at the level 5 (fully satisfied score, \%)

Design1: The solution for design 1

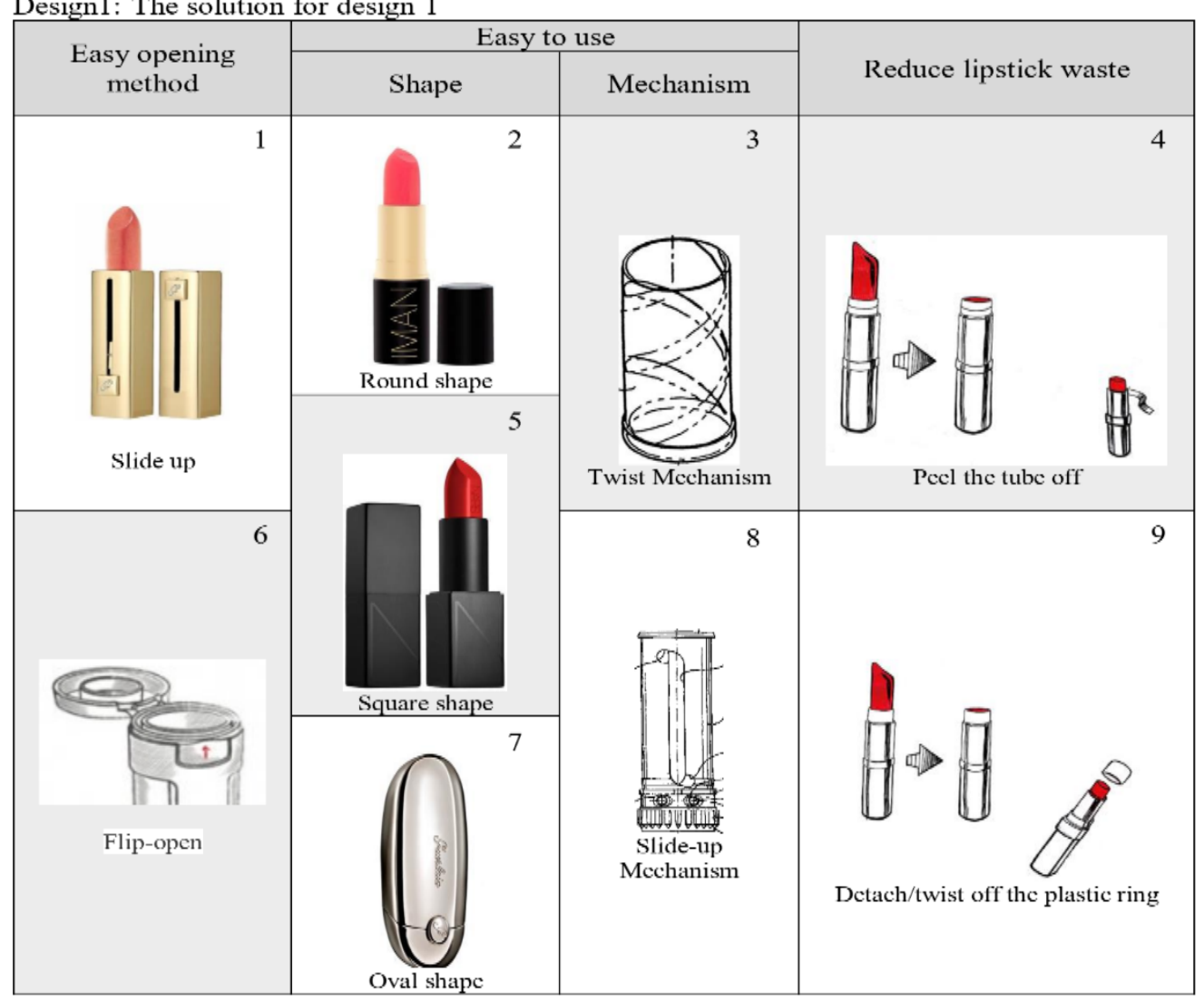

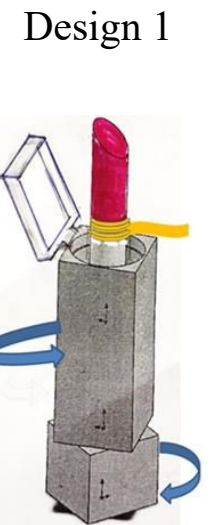

$(3,4,5$, and 6$)$

Figure 6 All possible alternatives of 10 different designs (design 1) using classification trees and combination table techniques 


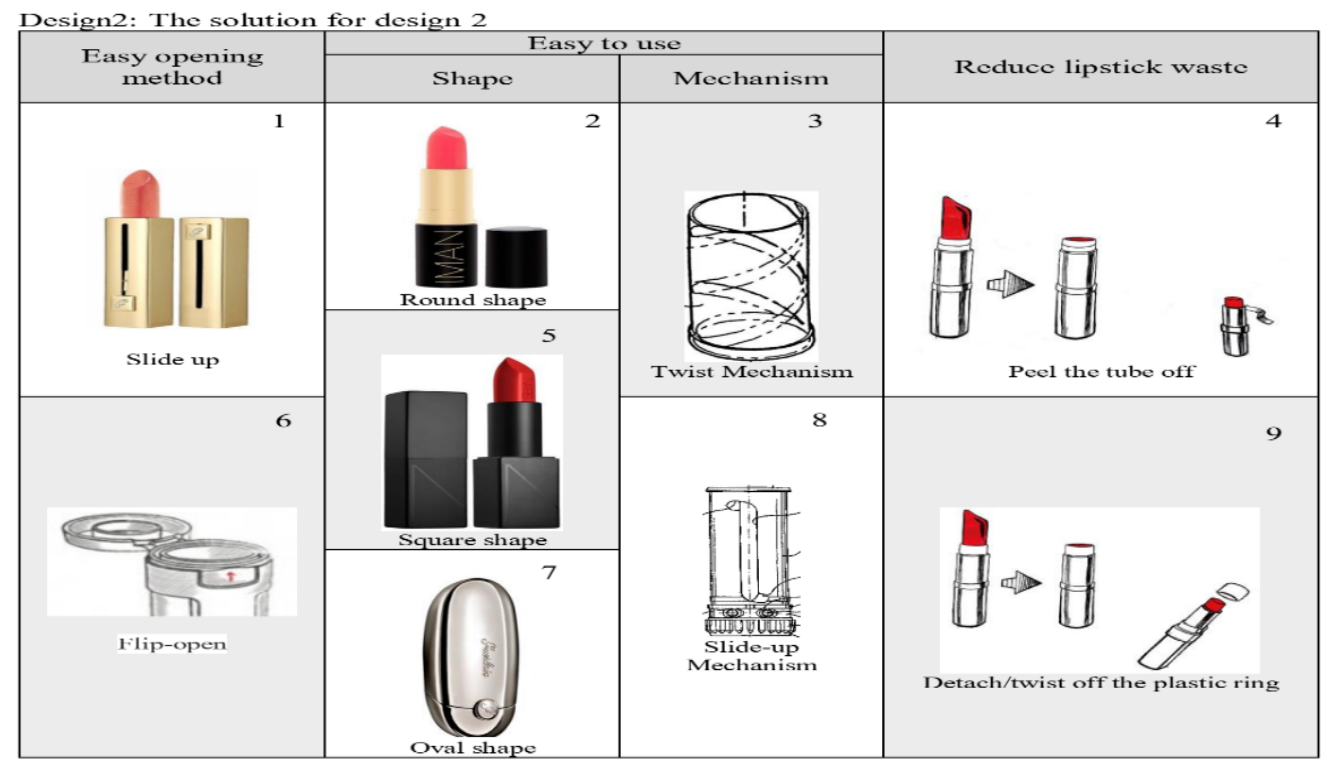

Design 2
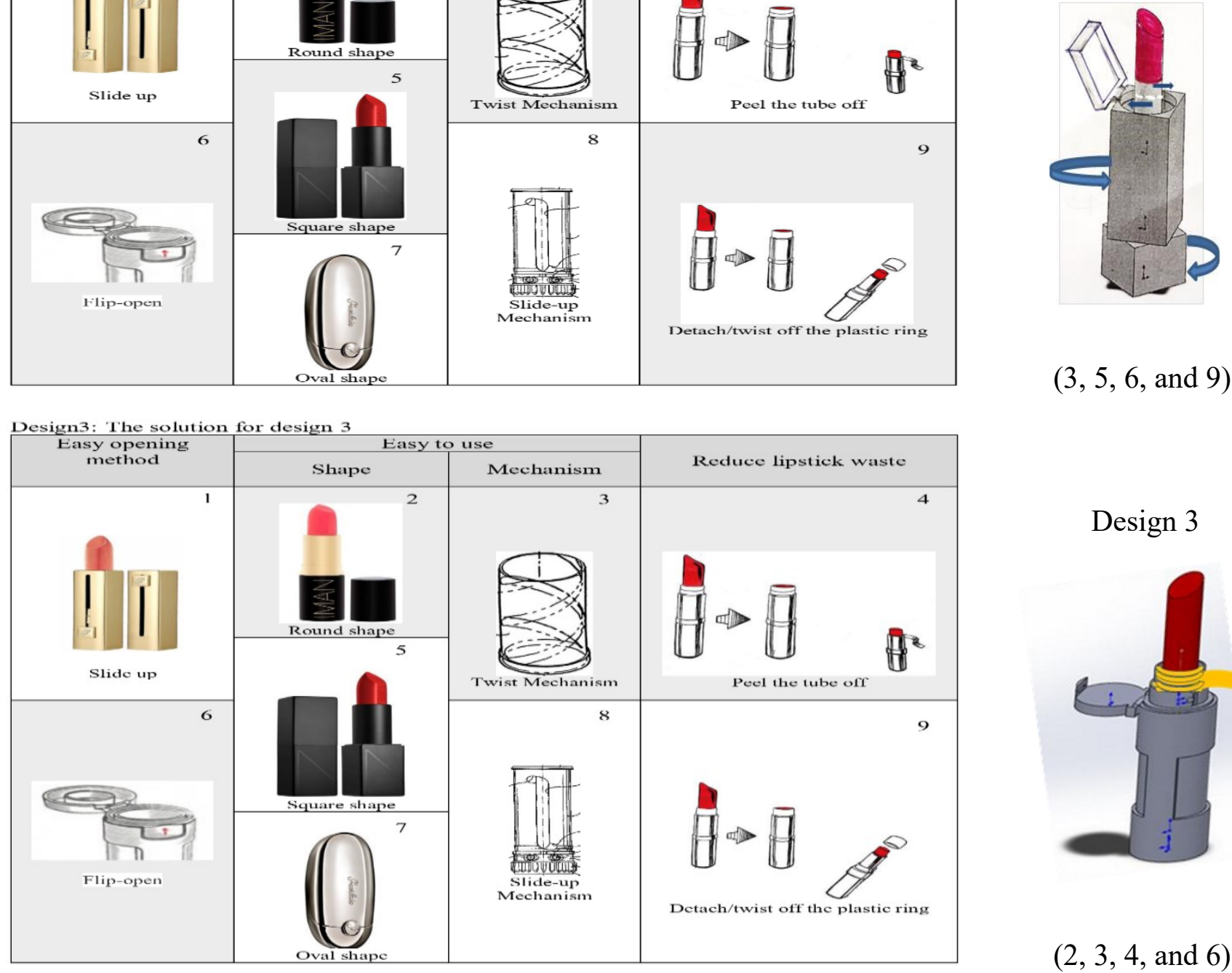

\section{$(3,5,6$, and 9$)$}

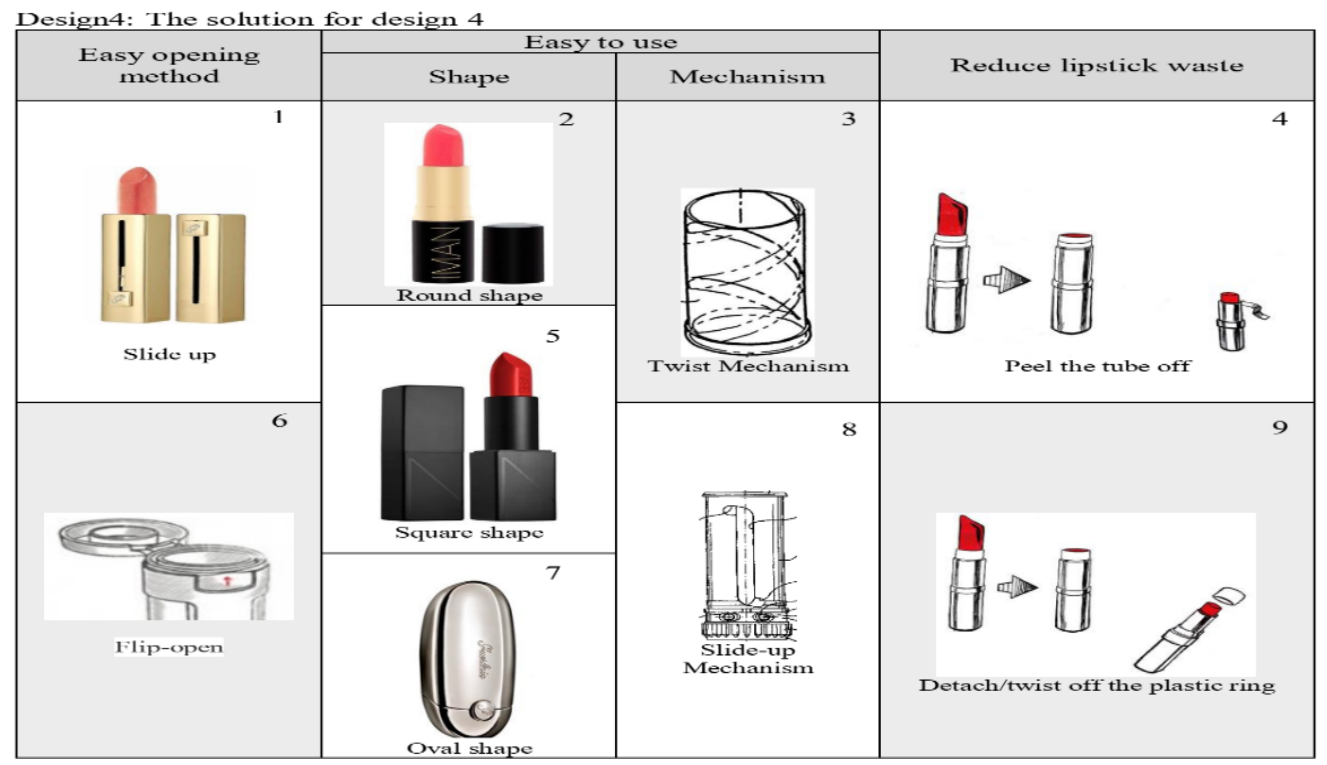

$(2,3,4$, and 6$)$

Design 3

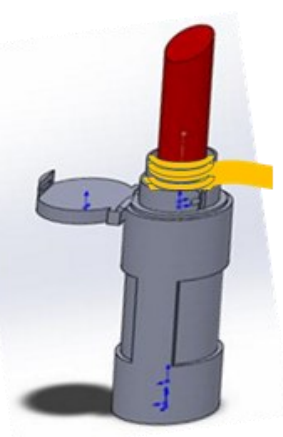

Design 4

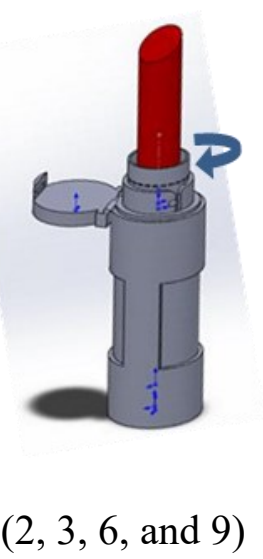

Figure 6 All possible alternatives of 10 different designs (design 2, 3, and 4) using classification trees and combination table techniques (con't) 

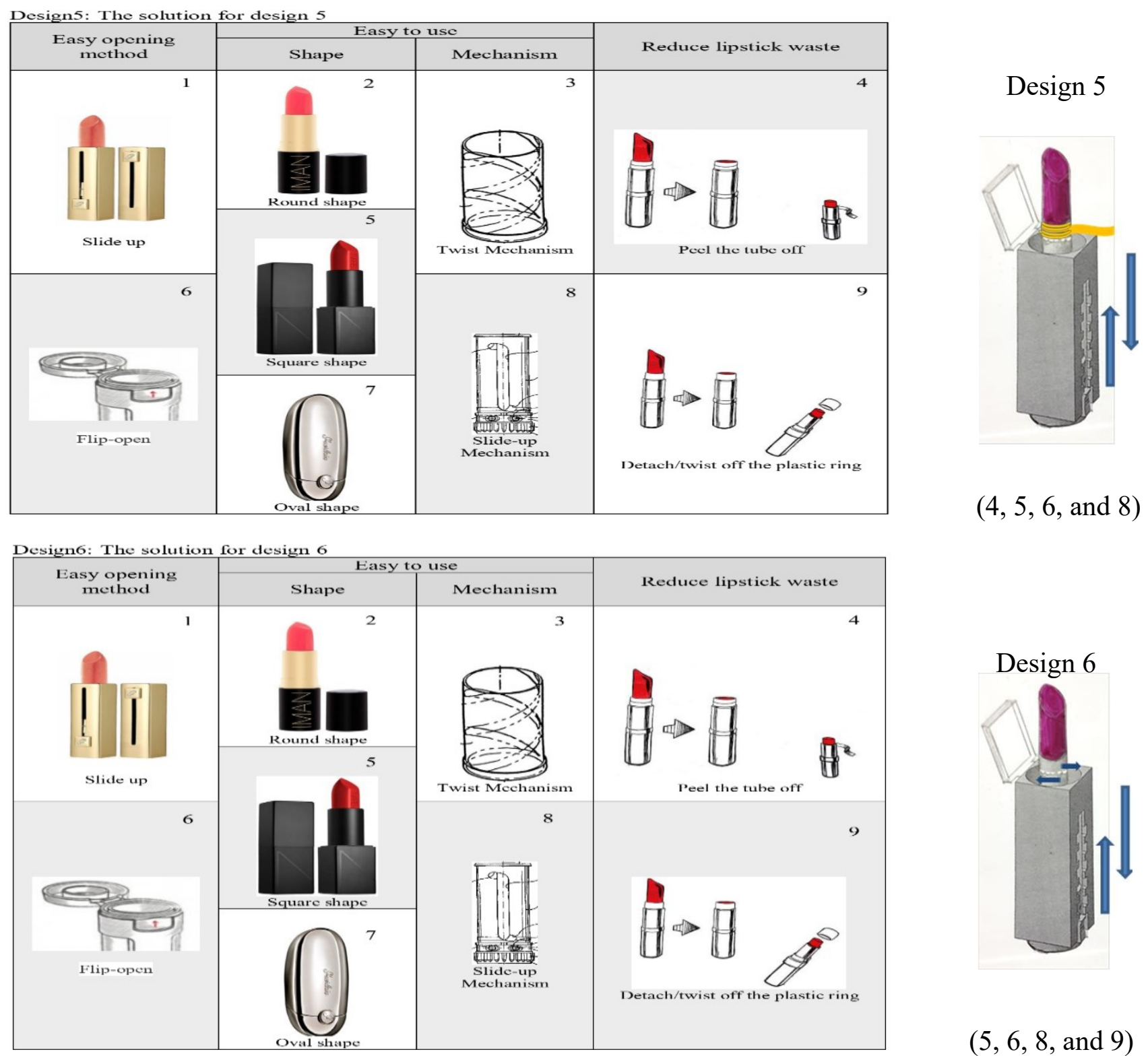

$(4,5,6$, and 8$)$
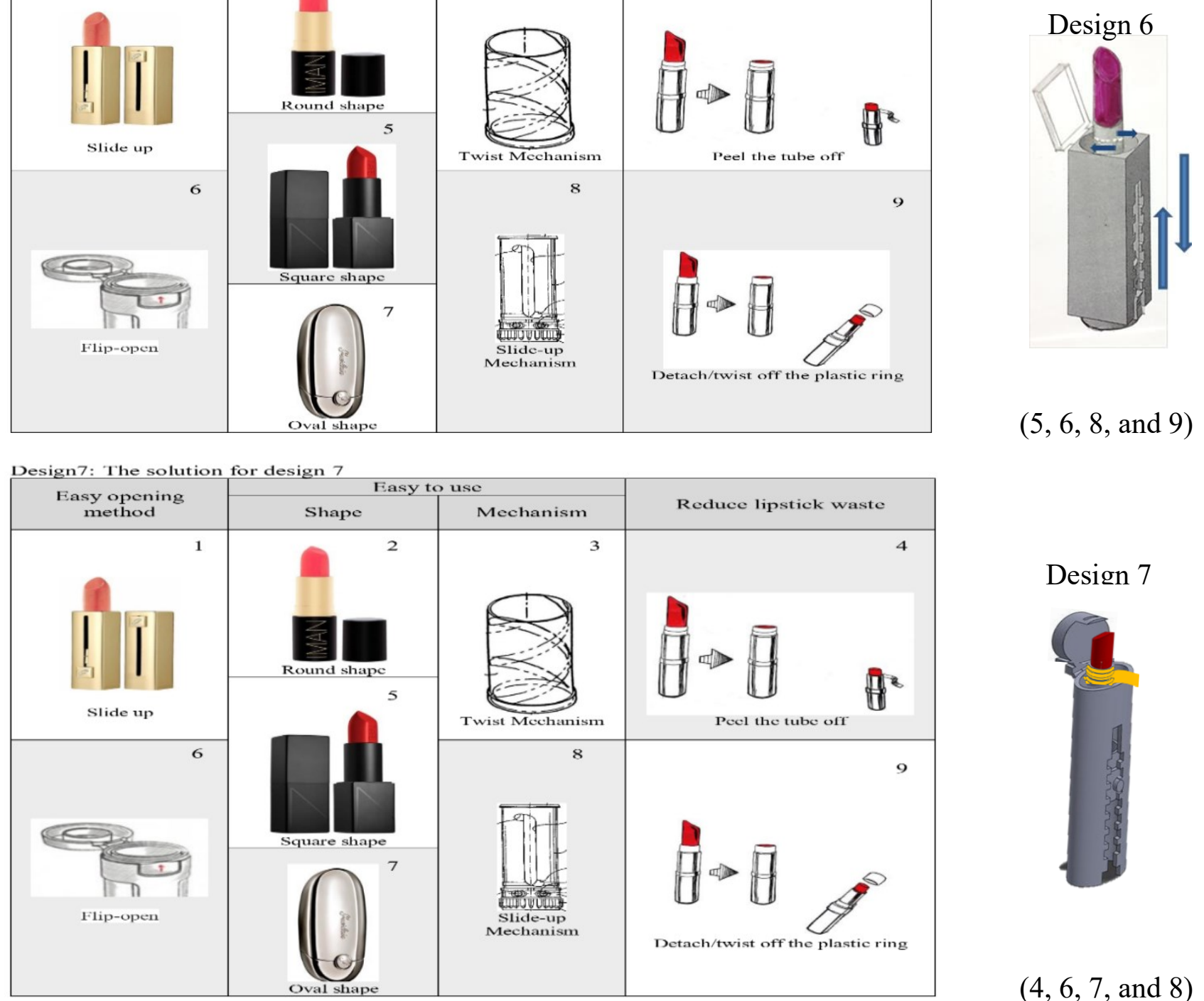

$(5,6,8$, and 9$)$

Design 7

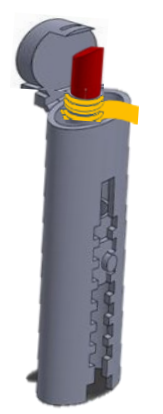

$(4,6,7$, and 8$)$

Figure 6 All possible alternatives of 10 different designs (design 5, 6, and 7) using classification trees and combination table techniques (con't) 


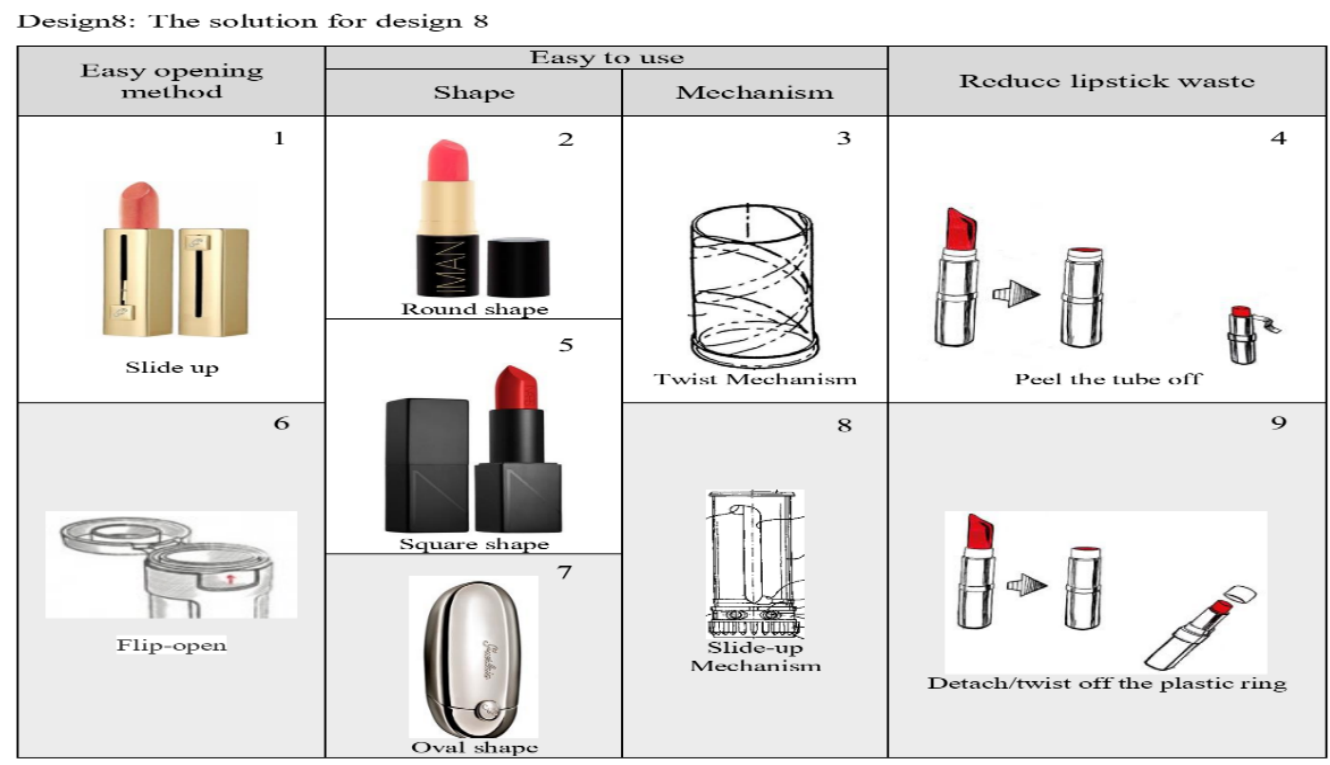

Design 8

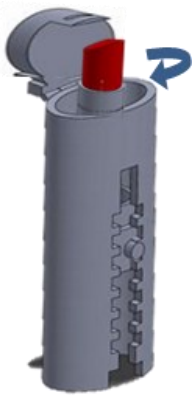

$(6,7,8$, and 9$)$

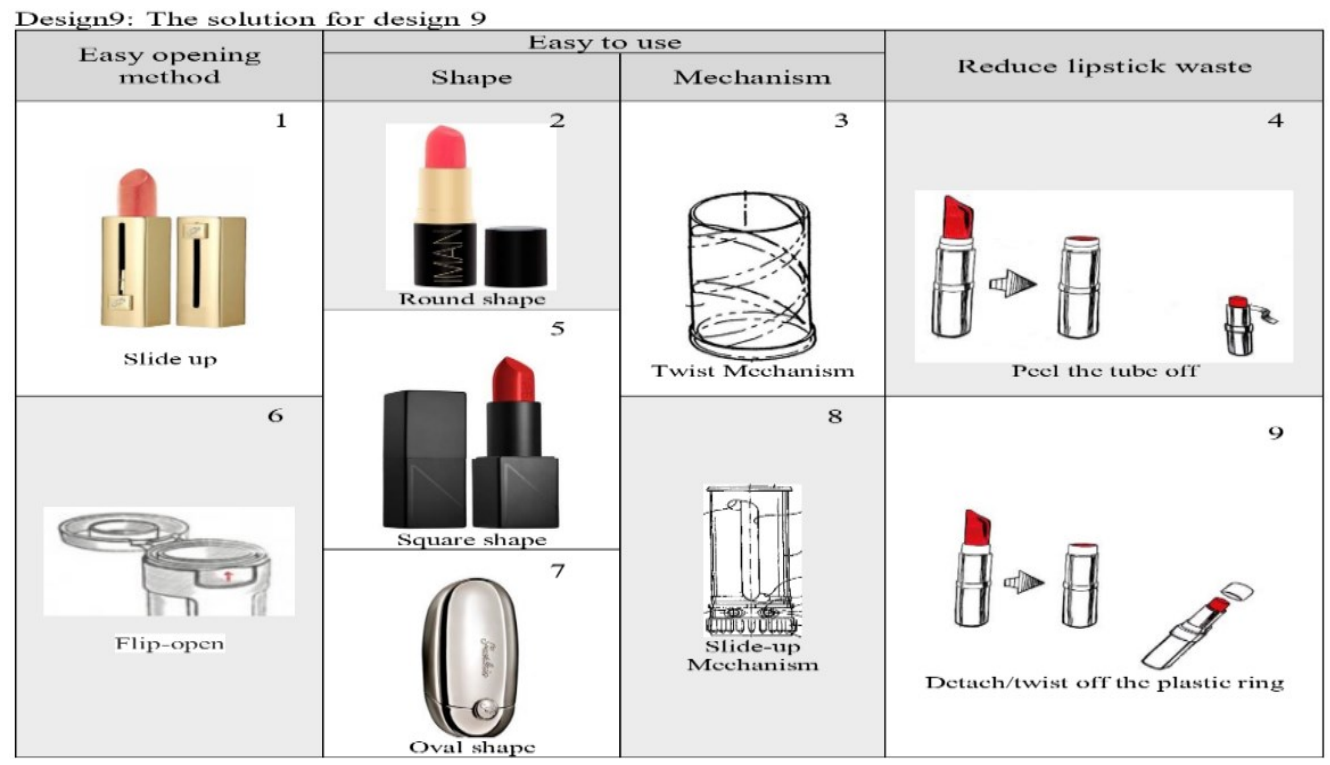

\section{Design 9}

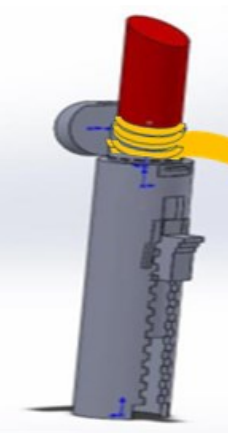

$(2,4,6$, and 8$)$

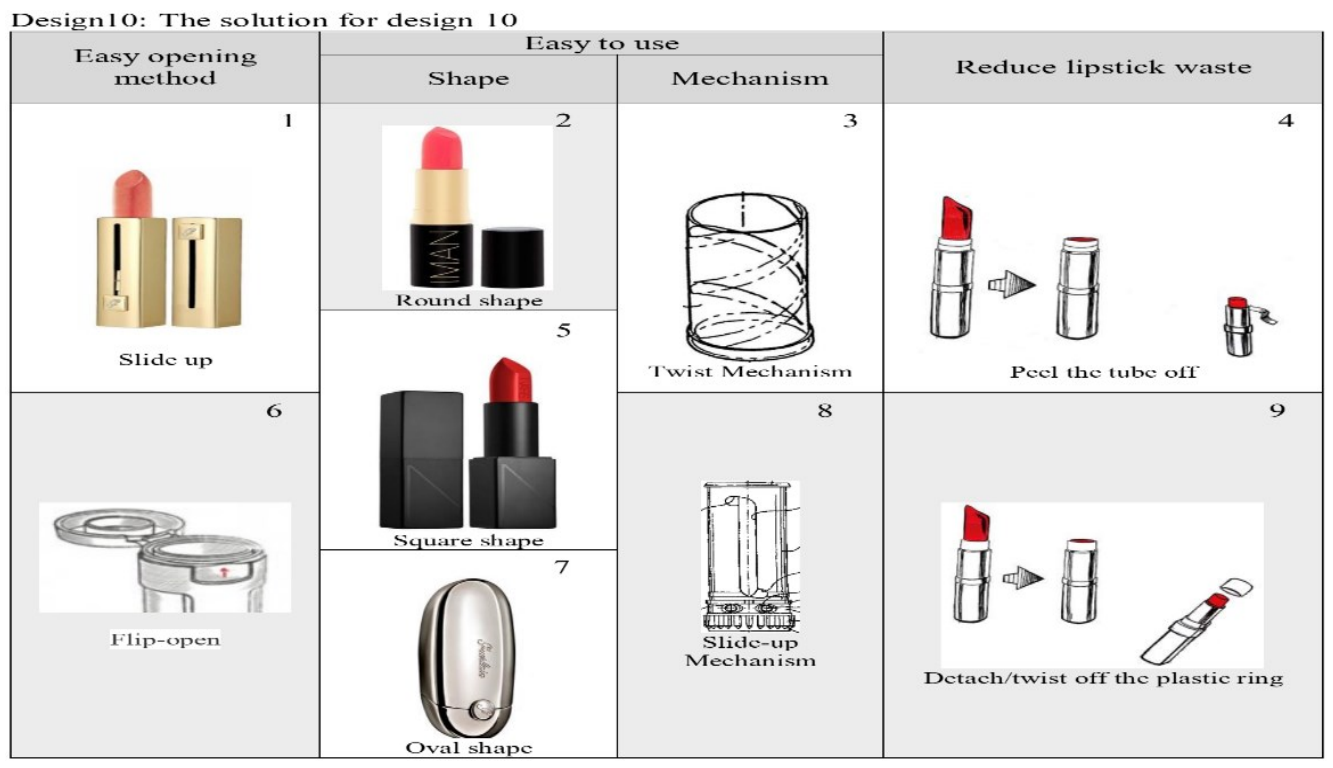

Design 10

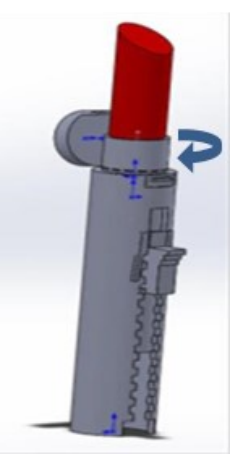

$(2,6,8$, and 9$)$

Figure 6 All possible alternatives of 10 different designs (design 8, 9, and 10) using classification trees and combination table techniques (cont'd) 
For screening of all possible design alternatives, the concept screening matrix between customer needs and all possible designs was established using design number 1 as a reference. As shown in Table 2, each design was scored as $+1,0$ or -1 for each criterion (customer needs) and four possible designs (design no.4, 6, 9 and 10), were further selected with the total scores of about $3,3,4$ and 5, respectively.

Table 2 Concept screening matrix

\begin{tabular}{|c|c|c|c|c|c|c|c|c|c|c|}
\hline \multirow[b]{2}{*}{ Criteria } & \multicolumn{10}{|c|}{ Design } \\
\hline & Reference & 2 & 3 & 4 & 5 & 6 & 7 & 8 & 9 & $\begin{array}{l}1 \\
0\end{array}$ \\
\hline \multicolumn{11}{|l|}{ Customer needs } \\
\hline 1. Easy to use & 0 & 0 & 0 & 0 & 1 & 1 & $\overline{1}$ & -1 & 1 & 1 \\
\hline $\begin{array}{l}\text { 2. Follow } \\
\text { material } \\
\text { industry } \\
\text { standards and } \\
\text { specifications }\end{array}$ & 0 & 0 & 0 & 0 & 0 & 0 & 0 & 0 & 0 & 0 \\
\hline $\begin{array}{l}\text { 3. Easy } \\
\text { opening } \\
\text { method }\end{array}$ & 0 & 0 & 0 & 0 & 0 & 0 & 0 & 0 & 0 & 0 \\
\hline $\begin{array}{l}\text { 4. Modern and } \\
\text { beautiful lipstick } \\
\text { case }\end{array}$ & 0 & 0 & 1 & 1 & 0 & 0 & $\overline{1}$ & -1 & 1 & 1 \\
\hline $\begin{array}{l}\text { 5. Environ- } \\
\text { mental-friendly }\end{array}$ & 0 & 0 & 0 & 0 & 0 & 0 & 0 & 0 & 0 & 0 \\
\hline $\begin{array}{l}\text { 6. Reduce } \\
\text { lipstick waste }\end{array}$ & 0 & 1 & 0 & 1 & 0 & 1 & 0 & 1 & 0 & 1 \\
\hline 7. Light weight & 0 & 0 & 1 & 1 & 0 & 0 & 1 & 1 & 1 & 1 \\
\hline $\begin{array}{l}\text { 8. Reusable } \\
\text { lipstick case }\end{array}$ & 0 & 0 & 0 & 0 & 1 & 1 & 1 & 1 & 1 & 1 \\
\hline Total & 0 & 1 & 2 & 3 & 2 & 3 & 0 & 1 & 4 & 5 \\
\hline
\end{tabular}

Note: screening criteria: $0=$ Equal significance, $1=$ More significance, $-1=$ Less significance

After the alternated design screening, the selected ones were weighted-ranking of measurement criteria, requiring the quantitative comparisons with subjective to the choices of weights and ranks. It started with an assignment of the significant rates of each criterion and then converted it into a percentage by dividing the sum of significant rates and multiplied with one hundred. The weight scores were then computed by multiplying the raw scores with the criteria weights. The total score of each design, which was the sum of the weight scores as indicated in Equation (1), was illustrated in Table 3. It could be seen that the best solution of all design candidates was design no. 10 with the overall highest score, well satisfying and contributing to all of those evaluation criteria.

$$
S_{j}=\stackrel{\circ}{a}_{i=1}^{n} w_{i} r_{i j}
$$

where $S_{j}$ is total score for concept $\mathrm{j}, \mathrm{n}$ is number of criteria, $r_{i j}$ is raw rating of concept $j$ for $i$ criterion and $w_{i}$ is weight for criterion.
Table 3 Concept scoring matrix

\begin{tabular}{|c|c|c|c|c|c|c|}
\hline \multirow{2}{*}{ Criteria } & \multirow{2}{*}{$\begin{array}{l}\text { Important } \\
\text { rating }\end{array}$} & \multirow{2}{*}{$\begin{array}{l}\text { Weight } \\
\text { (\%) }\end{array}$} & \multicolumn{4}{|c|}{ Design } \\
\hline & & & 4 & 6 & 9 & 10 \\
\hline \multicolumn{7}{|c|}{ Customer needs } \\
\hline 1. Easy to use & 9 & 14.06 & 4 & 4 & 5 & 5 \\
\hline $\begin{array}{l}\text { 2. Follow } \\
\text { material } \\
\text { industry } \\
\text { standards and } \\
\text { specifications }\end{array}$ & 9 & 14.06 & 3 & 3 & 3 & 3 \\
\hline $\begin{array}{l}\text { 3. Easy } \\
\text { opening } \\
\text { method }\end{array}$ & 9 & 14.06 & 4 & 4 & 4 & 4 \\
\hline $\begin{array}{l}\text { 4. Modern and } \\
\text { beautiful } \\
\text { lipstick case }\end{array}$ & 9 & 14.06 & 3 & 3 & 2 & 2 \\
\hline $\begin{array}{l}\text { 5. Environ- } \\
\text { mental-friendly }\end{array}$ & 9 & 14.06 & 5 & 5 & 5 & 5 \\
\hline $\begin{array}{l}\text { 6. Reduce } \\
\text { lipstick waste }\end{array}$ & 7 & 10.95 & 4 & 5 & 4 & 5 \\
\hline 7. Light weight & 7 & 10.95 & 3 & 3 & 5 & 5 \\
\hline $\begin{array}{l}\text { 8. Reusable } \\
\text { lipstick case }\end{array}$ & 5 & 7.80 & 3 & 3 & 5 & 5 \\
\hline Total $\left(S_{j}\right)$ & 64 & 100 & 3.67 & 3.78 & 4.05 & 4.15 \\
\hline
\end{tabular}

Note: Criteria for important rate are 1 to 9 and criteria for each design are 1 to 5 .

The best possible design alternative (Design 10: This case was assembled with the option no. 2, 6, 8, and 9 as shown by Figure 6) according to the evaluation criteria was selected and prototyped with the supports of SolidWorks Software and 3D Printer as shown by Figure 7. The roundshape casing was proper to keep it in the palm of hand, which encourages the use the slide-up and down mechanism. The twisting and pulling off of the plastic ring were also designed to reduce the waste. The cap lid was designed to flip up conveniently by using only one-hand which provides a better opportunity to be easily used all day long. Finally, the lipstick casing was designed to be reused, while the detached ring at the sleeve could be twisted around and removed conveniently which minimizes the waste of lipstick content.

\section{CONCLUSION AND RECOMMENDATION}

This study revealed that a combination of Telrad's questionnaire methodology to produce or exclude the questionnaire in accordance with the mission requirements and the Hybrid QFD Framework were successfully developed for a new product. Effective analysis of the satisfaction survey results pinpointed to the actual customer needs, which were integrated into the engineering characteristics and used as the critical parts to form the House of Quality (HoQ). The modified QFD (named CNQFD) was then initiated. Several possible alternatives of one-handed lipstick packaging were considered and the best one was selected and prototyped accordingly with the supports of SolidWorks Software and 3D Printer.

More specifically, several additional conclusions could be made such as: 
1. On-line questionnaire/satisfaction surveys were indispensable to obtain accurate results concerning the actual customer needs. Such surveys used a combination of Telrad's questionnaire procedure to include or exclude the questionnaire in accordance with the mission requirements and the Hybrid QFD Framework to develop a new product.

2. A detailed analysis of the satisfaction survey results revealed the actual customer needs which could be further incorporated into the engineering characteristics. After excluding a number of the questionnaires, the remaining ones could be further modified and became the critical parts to construct the final CN-QFD to form the House of Quality (HoQ).

3. Several designed alternatives were made by using classification trees and combination table techniques and the best resolution alternative for the sustainable one-handed lipstick packaging was finally selected and prototyped accordingly with the supports of Solid Work Software and 3-D Printer.

4. The round shape casing could help keeping the lipstick in the palm of the hand, thus enabling the easy use of the slide-up and slide-down mechanism. Moreover, the twisting and pulling off of the plastic ring were designed to reduce the waste.

5. The cap lid could be flipped up conveniently using only one-hand, which provided a better opportunity to be used suitably and effectively at all times. Finally, the lipstick casing could be reused and the severed ring at the sleeve could also be twisted around and removed conveniently which minimized the waste of lipstick content.

\begin{tabular}{|c|c|c|c|}
\hline \multirow{2}{*}{$\begin{array}{c}\text { Easy opening } \\
\text { method }\end{array}$} & Easy to use & Reduce lipstick waste \\
\cline { 2 - 3 } & Shape & Mechanism & \\
\hline & & & \\
\hline
\end{tabular}

\section{A new design of one-handed sustainable lipstick package}

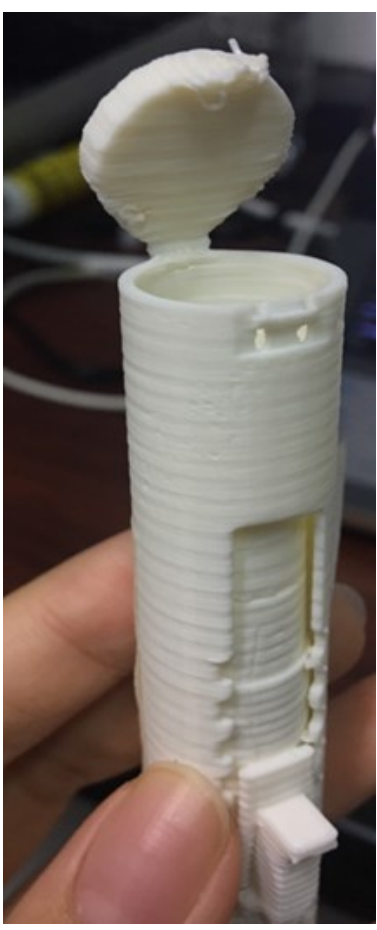

\section{Two pieces of component}

(Outer case and sleeve)

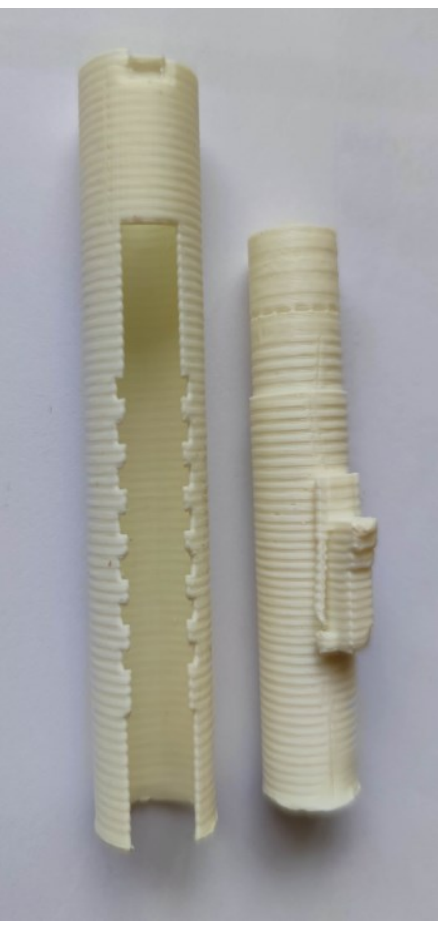

Figure 7 The most suitable design for a sustainable one-handed lipstick packaging 
Based on the findings, the following agenda for future researches are presented as followed:

1. There are some certain points needed to be addressed and recommended as different types of plastic and lipstick content used for the creation of prototype should be further explored regarding to their efficiency, durability, re-filling, and suitability of being reused for the one-hand sustainable lipstick packaging.

2. Integration of life cycle assessment (LCA) with the support of SimaPro software (an assessment of the environmental aspects and potential associated impacts) and environmentally friendly decision model for sustainable new product development (SNPD) should be further investigated. Environmental variables in cooperation with manufacturing new product information and improvement strategies have also been initiated accordingly.

\section{ACKNOWLEDGEMENT}

The authors would like to sincerely thank all staffs and members of Kainuma Research's laboratory, Faculty of Systems Design, Tokyo Metropolitan University, Japan, for their support while creating this publication. Special thanks are also due to the Tokyo Human Resources Fund for City Diplomacy for the financial support.

\section{REFERENCES}

Bouchereau, V., and Rowlands, H. (2000). Methods and techniques to help Quality Function Deployment (QFD). Benchmarking: An International Journal 7(1), pp. 8- 20.

Chuang, P.T. (2001). Combining the analytic hierarchy process and quality function deployment for a location decision from a requirement perspective. International Journal of Advanced Manufacturing Technology 18(11), pp. $842-849$.

Curtis C.C., and Ellis L.W. (1998). Satisfy customers while speeding R\&D and staying profitable. Res. Technology Management 41, pp. $23-24$.

Das, K. (2020). Planning environmental and economic sustainability in closed-loop supply chains. Operations and Supply Chain Management 13(1), pp. 64 - 81.

Das, K., and Mitra, A. (2018). Integrating Sustainability in the Design and Planning of Supply Chains. Operations and Supply Chain Management 11(4), pp. 161 - 185.

Dimancescu, D., and Dwenger, K. (1996), World-Class New Product Development: Benchmarking Best Practices of Agile Manufacturers, AMACOM, New York.

Glushkovsky, E. A., Florescu, R. A., Hershkovits, A., and Sipper, D. (1995). Avoid a Flop: Use QFD With Questionnaires. Quality Progress 28 (6), pp. 57 - 62.
Grandviewresearch (2019). Lipstick Market Size Worth \$18.9 Billion By 2025 CAGR: 7.4\%. Available from: https://www.grandviewresearch.com/press-release/globallipstick-market/ [accessed December 17, 2020].

Hassini, E., Surti, C., and Searcy C. (2012). A literature review and a case study of sustainable supply chains with a focus on metrics. International Journal of Production Economics 140, pp. $69-82$.

Kainuma, Y., and Amano, D. (2018), New Product Development Method based on Customer Satisfaction, In Japan Industrial Management Association (JIMA) Research Division of Management Mathematics (ed): Advanced Management Science and Its Application, Izumi Syuppan.

Kolodner, J. (1993), Case-Based Reasoning. Calif.: Morgan Kaufmann, San Francisco.

Lin, Y.H., and Tseng, M.L. (2016). Accessing the competitive priorities within sustainable supply chain management under uncertainty. Journal of Cleaner Production 112, pp. 2133 2144.

Mujkić, Z., Qorri, A., and Kraslawski, A. (2018). Sustainability and Optimization of Supply Chains: a Literature Review. Operations and Supply Chain Management 11(4), pp. 186 199.

Parasuraman, A. (1991), Marketing Research - 2nd Edition. Addison-Wesley Publishing Company, Inc. Massachusetts.

Romero-Hernández et al. (2021). A Supply Chain Selection Method for Early-Stage Companies Based on an Adapted QFD Approach. Operations and Supply Chain Management 14 (2), pp. $133-147$.

Sullivan, L.P. (1986). Quality Function Deployment: A system to assure that customer needs drive the product design and production process. Quality Progress 2, pp. $39-50$.

Tsai, Y. C., Chin, K. S., and Yang, J. B. (2002). A Hybrid QFD Framework for New Product Development. Asian Journal on Quality 3(2), pp. 138 - 158.

Tundys, B. (2018). Use of Quantitative and Qualitative Methods for Modelling Green Supply Chains. Operations and Supply Chain Management 11(2), pp. 82 - 97.

Tzu-Yun Wang, Hsin-I Hsiao, and Wen-Chieh Sung. (2019) Quality function deployment modified for the food industry: An example of a granola bar. Food Sci Nutr. 7, pp. $1746-$ 1753.

Williams, A., Kennedy, S., Philipp, F., and Whiteman, G. (2017). Systems thinking: a review of sustainability management research. Journal of Cleaner Production 148, pp. 866 - 881 .

Wolf, C., and Seuring, S. (2010). Environmental impacts as buying criteria for third party logistical services. International Journal of Physical Distribution \& Logistics Management 40, pp. $84-102$.

Wu, Z., and Pagell, M. (2011). Balancing priorities: Decisionmaking in sustainable supply chain management. Journal of Operations Management 29(6), pp. 577 - 590.

Thanyatorn Fongsatitkul is a Ph.D. candidate in the Department of Electrical Engineering and Computer Science, Graduate School of Systems Design at Tokyo Metropolitan University, Japan under the financial support from Tokyo Human Resources Fund for City Diplomacy Scholarship Program. She graduated with B.Eng (Industrial engineering), Chiang Mai University and M.Eng (Industrial and manufacturing engineering), Asian Institute of Technology, Thailand. Her research interests include product packaging design and supply chain management.

Yasutaka Kainuma is currently a Professor at the Department of Electrical Engineering and Computer Science, Graduate School of Systems Design, Tokyo Metropolitan University, Japan. His research interests include Operations Management, Closed-Loop Supply Chain, Humanitarian Supply Chain, and Disaster Relief Supply Chain and Supply Chain Risk Management. His papers have been published in the International Journal of Production Economics, Asian Journal of Quality, Journal of Precision Engineering and Manufacturing Green Technology and Operations and Supply Chain Management: An International Journal among others. He has served as President of Japan Operations Management \& Strategy Association 
Fongsatitkul \& Kainuma: Integrating a VOC to Create the CN-QFD for a Sustainable New Product Development Operations and Supply Chain Management 14(4) pp. 520 - 535 (C) 2021

(JOMSA), Vice President of Japan Industrial Management Association (JIMA) and Board of Trustees Member of the International Foundation for Production Research - Asia Pacific Region (IFPR-APR). 